\title{
CDIO-based Redesign of a Traditional Undergraduate-level Course on Air- craft Flight Dynamics and Control
}

\section{Dr. Srikanth Gururajan, Saint Louis University, Parks College of Eng.}

Dr. Srikanth Gururajan is an Assistant Professor in the Department of Aerospace and Mechanical Engineering at the Parks College of Engineering, Aviation and Technology at Saint Louis University. He received his PhD. in Aerospace Engineering from West Virginia University, Morgantown, West Virginia.

Dr. Gururajan's teaching interests are in the areas of Flight Dynamics and Controls and believes that student aerospace design competitions are ideal avenues for students to express their creativity while complementing the knowledge gained in the classroom with hands-on experience as well as promoting greater collaboration and learning across disciplines.

Dr. Gururajan's research interests are interdisciplinary and in the fields of fault tolerant flight control, parallel \& distributed computing, real time systems, experimental flight testing using small UAS and UAS, and the design/development of natural language interaction with drones.

\section{Dr. Claire L. A. Dancz, Clemson University}

Dr. Claire L. A. Dancz is a Research Associate for Education Systems at Watt Family Innovation Center and Adjunct Faculty in the Department of Engineering and Science Education at Clemson University. Dr. Dancz's research interests include creativity in engineering, technology-rich learning environments, STEM faculty development, team formation with conation, and sustainable civil engineering. She earned her Ph.D. in Sustainable Engineering from Arizona State University. She serves as external evaluator on engineering and science education research projects, corresponding member of the Formal Engineering Education Subcommittee to the Committee on Sustainability at the American Society for Civil Engineering, teaches an interdisciplinary Creative Inquiry course on Conation and Creativity in Engineering, and is the director for NAE Grand Challenge Scholars Program at Clemson.Dr. Danczhas been a Kolbe ${ }^{\mathrm{TM}}$ Certified Consultant since 2013 and consults on conation and team formation. 


\title{
Conceive - Design - Implement - Operate (CDIO) based redesign of a traditional aircraft flight dynamics and control course
}

\begin{abstract}
This work-in-progress paper describes a proposed effort to redesign a traditional course in flight dynamics, stability and control at Saint Louis University, St. Louis, MO, through the incorporation of CDIO techniques. In the proposed redesigned course, students will have an opportunity to move beyond (but not exclude) closed-ended homework and/or programming projects in Matlab, and explore the potential for validating their learning though hands-on experimental flight tests, using a custom designed Unmanned Aerial System (UAS). The envisioned flight test experiments would include opportunities to address several crucial concepts in flight dynamics, stability and control, including the determination of the aircraft's aerodynamic characteristics, stability and control derivatives, validity of the small perturbation assumptions, as well as the approximations to dynamics (short period, roll and Dutch roll for example). Upon implementation, we anticipate to assess the educational outcome by asking the question "whether this approach (1) helps students think critically about aircraft stability and control and whether (2) students positively receive the field experience", through student produced reflections captured in pre-and post-surveys. We hypothesize that this redesign will result not only in increased student learning, engagement and long-term retention of flight dynamics concepts, but also introduce the students to a "systems type" thinking, as applied to UAS.
\end{abstract}

\section{Introduction}

Over the last decade there has been a significant shift from the use of fixed wing remote controlled aircraft to multirotor platforms, thanks primarily to a coolness factor, relatively inexpensive imports as well as their flexibility in terms of flying, hover and carrying various imaging payloads. But, with user sentiment shifting from "Can you build a Quad, Hex or Octo copter, it is cool", to "What tasks can your Unmanned Aerial System accomplish?", and from recreational use of drones to real world use, fixed wing platforms are regaining favor in industrial and commercial applications. While multi-rotors are currently popular platforms to perform various tasks (including some beyond-line-of-sight flights) fixed wing UAS have a significant advantage when it comes to endurance and the capacity to carry payload; they can carry more payload, fly for longer and are more forgiving to failures. These are critical factors on the side of fixed wing UAS, considering that the current climate for UAS operations limit most flights to within line of sight of the operator and other restrictions, with beyond line of sight (BLOS) and other flights allowed with FAA exemptions. But, it is not inconceivable that in the near future, beyond line of sight flights are more extensively adopted, enabling operators to execute long distance, long endurance flights with complex mission goals.

Tracking back from this likely UAS deployment scenario, the requirements for undergraduate aerospace engineers to embark on successful careers in the industry is likely going to be the ability to move beyond classroom knowledge of flight concepts to being able to Conceive - Design Implement - Operate (CDIO) such platforms within any mission parameters.

The CDIO approach was conceived to fill the gap in "real-world engineering" skills of undergraduate students (CDIO initiative), with a vision to focus on the fundamental concepts in engineering. Currently, a number of academic institutions as well as members from the industry participate in the CDIO activities. A number of studies have documented the use of such techniques 
in redesigning their curriculum in various fields, from operating like a small company (Säisä, 2017) undergraduate design projects (Takemata, 2013), a course in electronics (Svensson, 2012) and systems engineering (Hsu, 2007).

The most relevant aspect of the CDIO approach in the context of our course curriculum redesign is that it has been shown to be successful in fostering long term retention of fundamental engineering concepts taught in the classroom. At our institution (as perhaps with others), constraints on time and resources has resulted in a limited, informal adoption of some aspects of the CDIO approach (without a tangible, consequential hands-on experimental component), and has been restricted mostly to the capstone course. In our effort, we propose to incorporate the CDIO concept into the structure of a traditional course on aircraft flight dynamics, stability and control by redesigning the course curriculum to include hands-on design and flight testing modules at appropriate points, while meeting ABET goals.

\section{Current structure of Stability and Control Course}

As it currently stands, in the aerospace engineering curriculum at Parks College of Engineering Aviation and Technology at Saint Louis University, aircraft flight dynamics and controls is taught as a required course in the fall semester for undergraduate students in their senior year. The course is structured to provide an intense introduction to aircraft dynamics, starting from the fundamentals, addressing derivation of equations of motion, static and dynamic stability, derivation of the mathematical models of the aircraft and building all the way up to the design of stability augmentation systems such as yaw and pitch dampers. Using Matlab based programming assignments and projects, this approach has shown to provide a broad knowledge of the fundamentals and insights into complex interactions that drive the dynamics of an aircraft, and has produced graduates who have successful careers in the aerospace industry, with major aerospace companies, and in graduate school. A sample of such projects and our current course syllabus are included as appendices to this manuscript, for the reader's reference.

\section{Vision for the future}

As previously mentioned, we anticipate that in the near to mid-term in the future, applications of UAS will transition beyond the current Line-of-Sight (LoS) limitations, thus expanding the horizon for long distance, long endurance UAS flights. This we believe will spur small and medium scale entrepreneurs to drive innovation in this space at a faster pace and that their workforce needs would shift to engineering graduates with a broad systems type skill set - students who have had a good theoretical foundation along with design, fabrication, implementation and operational experience. To address this anticipated need, through this paper, we propose to redesign the existing course syllabus (on flight dynamics, stability and control) to incorporate the concepts of CDIO - and to address certain targeted topics with the intention to incorporate these changes in the coming fall semester (fall 2019), pending approval by our college's academic affairs committee.

\section{Proposed Course Redesign with CDIO}

In the revamped course curriculum, we intend to integrate the use of a custom fabricated fixed wing UAS with the course material. As and when relevant topics are covered in the class, students will be tasked to apply that knowledge to an aircraft of known configuration; for instance, when background aerodynamic topics are reviewed in class, the students will be able to apply that to the known aircraft (Cessna 172, for example) and calculate its aerodynamic characteristics, lift-curve 
slope, aerodynamic center and static margin, for instance, through traditional Matlab based programming exercises. This 'closed-ended' exercise would serve as a baseline as the students will be able to check their work and the results from that against those in existing literature. Following that, the subsequent exercise for the students would be to determine the same characteristics of the custom built UAS, the SLU Sharpshooter (Figure 1). As the course progresses, and when aircraft dynamics (longitudinal and lateral-direction) are modeled under small perturbation assumptions, students will be tasked to build upon the computer code they developed earlier, to determine the stability and control derivatives, the resulting mathematical model of the UAS, and subsequently simulate its open loop dynamics.

In line with published literature highlighting the efficacy of hands-on experimental components in enhancing learning and retention of concepts taught in the classroom, we believe that in the context of aircraft dynamics, stability and control, flight testing experience is a critical component that could serve to reinforce concepts that have been learned in the classroom. This has been missing in our curriculum (as well as a majority of other academic institutions) mainly because it is hard to incorporate into a traditional course syllabus, given the logistics (travel to a flight field, prevailing weather conditions, transportation etc.) and risks of flight testing (crashes of the UAS, unanticipated failures and/or loss of data). The availability of low cost hardware and custom built UAS platform at Parks College of SLU, as well as the extensive experience of the authors with the design, fabrication of the UAS and the flight testing process affords us the possibility of incorporating this into the curriculum, and be able to mitigate the risks associated with UAS flight testing.

We envision the following tasks to map the concepts of CDIO as applied to an existing UAS testbed:

Conceive: As the students are introduced to the fundamental concepts in class, small projects with tight execution times (approx. 1 week duration) will be used to conceive performance specifications for the UAS; for example, the requirement could be that UAS be capable of carrying a payload (of some finite weight, dimensions or volume), and have certain dynamic characteristics (short period or Dutch roll damping ratio and natural frequency).

Design and Implement: Based on the performance specifications, the students would be tasked to design the layout of the payload within the UAS to achieve (potentially) the conceived performance. We anticipate that during this task, students will encounter certain limitations on actual implementation of certain payload configurations on the UAS, due to its existing structure. This should lead to a redesign/reevaluation loop where the students evaluate alternate configurations to still meet the conceived performance specifications. There is also the likelihood of not being able to meet the conceived specifications, thus requiring appropriate justifications.

Operate: With the ability to conduct flight tests, the students would be able to evaluate their design choices, with real flight data. As the class proceeds and advanced topics such as the design and evaluation of Stability Augmentation Systems (Yaw and Pitch damper, for example) are covered, the students will be able to apply those concepts to the redesign loop. Furthermore, they would be able to simulate the performance of the UAS with and without the compensators, followed by verification through flight tests.

It is important to note that our intent is not to redesign this course to replace capstone projects; those projects are much more comprehensive and involve other topics including, but not limited 
to aircraft structures and propulsion. The current course framework is listed, along with proposed CDIO inspired changes, in Table 1, and the syllabus (current and proposed CDIO based revision) is in Appendices A and B respectively.

Table 1: Current Course Framework and Proposed CDIO Based Additions

\begin{tabular}{|c|c|c|}
\hline Existing course outline and topics & $\begin{array}{c}\text { Current } \\
\text { assignments/projects }\end{array}$ & $\begin{array}{c}\text { Proposed CDIO inspired additions } \\
\text { (project based) }\end{array}$ \\
\hline $\begin{array}{l}\text { 1. Derivation of the equations of } \\
\text { motion of a rigid aircraft. } \\
\text { 2. Review of background material on } \\
\text { Aerodynamics. }\end{array}$ & $\begin{array}{l}\text { - Develop computer code } \\
\text { (scripts) of aircraft } \\
\text { dynamics and extract } \\
\text { aerodynamic parameters } \\
\text { for a fixed wing model } \\
\text { aircraft }\end{array}$ & $\begin{array}{l}\text { - Introduce the SLU Sharpshooter } \\
\text { UAS } \\
\text { - Determine its geometrical and } \\
\text { inertial parameters }\end{array}$ \\
\hline $\begin{array}{l}\text { 3. Modeling of aerodynamic and } \\
\text { thrust forces and moments. } \\
\text { 4. Static stability and controls in } \\
\text { longitudinal and lateral - } \\
\text { directional motion. } \\
\text { 5. Longitudinal and Lateral- } \\
\text { directional dynamic stability. }\end{array}$ & $\begin{array}{l}\text { Extend scripts to include } \\
\text { modeling of aerodynamic } \\
\text { and thrust forces and } \\
\text { estimate static and dynamic } \\
\text { stability of an existing } \\
\text { aircraft }\end{array}$ & $\begin{array}{l}\text { - Extract stability and control } \\
\text { derivatives } \\
\text { - Determine static and dynamic } \\
\text { stability } \\
\text { - Predict dynamic performance: short } \\
\text { period, roll and Dutch roll dynamics } \\
\text { - Flight test experiments to validate } \\
\text { predictions }\end{array}$ \\
\hline 6. Stability sensitivity analysis. & $\begin{array}{l}\text { - Change aircraft } \\
\text { configuration (for example, } \\
\text { C.G); predict dynamics }\end{array}$ & $\begin{array}{l}\text { - Extend variations in configurations } \\
\text { (airfoil selection, dihederal, } \\
\text { empennage design etc.) }\end{array}$ \\
\hline $\begin{array}{l}\text { 7. Aircraft response to control inputs; } \\
\text { manual and automatic control of } \\
\text { flight; stability augmentation } \\
\text { system (SAS) design; classical and } \\
\text { state space methods design and } \\
\text { analysis. }\end{array}$ & $\begin{array}{l}\text { Design SAS; run } \\
\text { simulations, predict } \\
\text { dynamics (Note: this part } \\
\text { or a portion thereof would } \\
\text { be replaced with flight } \\
\text { testing activities) }\end{array}$ & $\begin{array}{l}\text { Experimental validation through } \\
\text { flight tests on SLU Sharpshooter } \\
\text { UAS (this will be conducted as a } \\
\text { team project) }\end{array}$ \\
\hline
\end{tabular}

We anticipate that these proposed CDIO-inspired course additions will benefit students by engaging them in a field-testing experience in real world conditions, presenting them with welldefined modules with manageable uncertainties, and focusing only on aircraft dynamics and controls - unlike capstone projects.

\section{Custom Designed UAS Platform}

For the purposes of this effort, we intend to use a custom designed fixed wing UAS - the $S L U$ Sharpshooter. The UAS is designed so that it is modular - with the exception of the fuselage and the integrated mid-section of the wing, all other components can be switched out, including the empennage, the wing section(s) and its geometry (for instance, dihederal can be introduced or removed through special dihedral pin inserts). The specifications and pictures of the Sharpshooter UAS are listed below in in Table 2. The UAS in Figure 1 has been flown a number of times and is intended to serve as a bridge platform until the newer platform shown in Figure 2 has been flight tested and validated. 
Table 2: Specifications of SLU Sharpshooter fixed-wing UAS

\begin{tabular}{|c|c|c|}
\hline & & "SLU Sharpshooter” UAS Platform \\
\hline \multirow{4}{*}{ 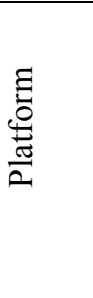 } & Geometry \& Weight & 96" - Length; 144" - Wingspan; 17 lbs (Empty) \\
\hline & Payload Capacity & $\sim 10$ lbs. \\
\hline & Operational Specifications & $400 \mathrm{ft}$. ceiling, 30-80 Knots (Flight speed), line of sight \\
\hline & Flight Endurance & $\begin{array}{l}\sim 20 \text { minutes (Electric Propulsion) } \\
\sim 60 \text { minutes (Gasoline Propulsion) }\end{array}$ \\
\hline 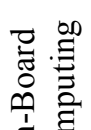 & Flight control computer & $\begin{array}{l}\text { COTS Flight controllers (Pixhawk or its variants) } \\
\text { Custom Built PC-104 format on-board main computer. } \\
\text { In-House developed Flight control software }\end{array}$ \\
\hline \multirow{3}{*}{ 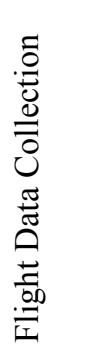 } & Telemetry & $\begin{array}{l}\text { Downlink and Uplink capability. } \\
\text { - } 915 \mathrm{MHz} \text { RF Modem (COTS) }\end{array}$ \\
\hline & On-board sensors & $\begin{array}{l}\text { Static and dynamic pressure measurements. } \\
\text { Digital IMU with angular rate sensors and accelerometers. } \\
\text { Surface position measurements. } \\
10 \mathrm{~Hz} \text { GPS receiver. }\end{array}$ \\
\hline & On-Board Data Storage & Recording of all flight data on Secure Digital cards. \\
\hline
\end{tabular}

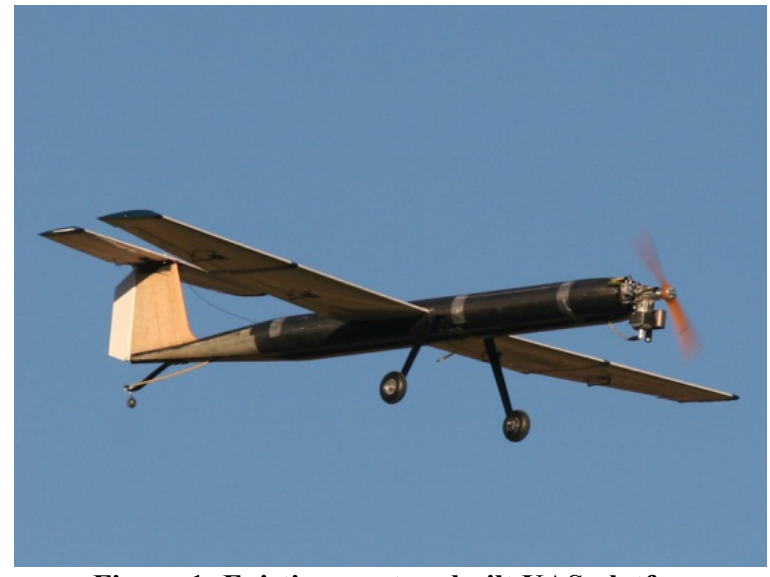

Figure 1: Existing, custom built UAS platform

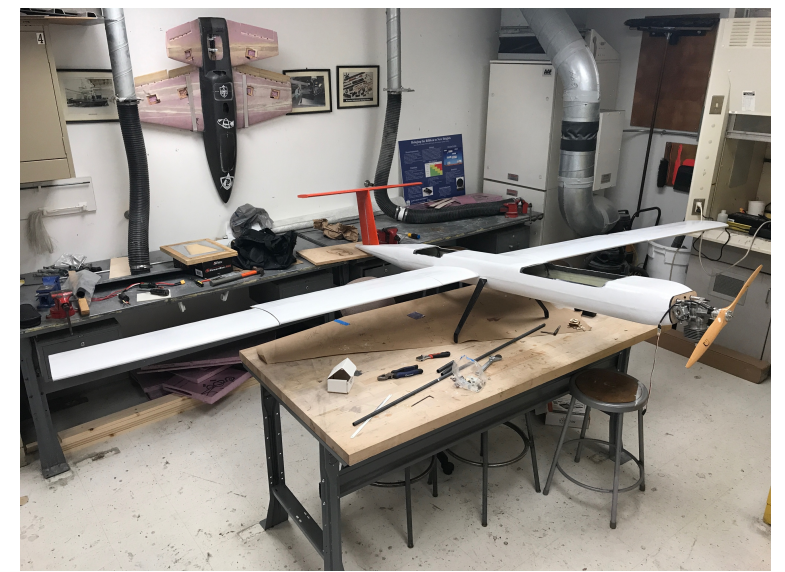

Figure 2: Next generation, custom built, modular UAS platform

\section{Measurement of Educational Outcomes}

At Parks College of Saint Louis University, a typical cohort of students majoring in aerospace engineering averages about 25-30 students and we expect this to be true for the next three to four years, based on current (and projected future) student enrollment data. At the end of this course, students should be able to (1) demonstrate the ability derive fundamental equations that describe the aircraft dynamics as well as to determine the stability and flight control characteristics of an aircraft, (2) demonstrate understanding of how design parameters related to aircraft geometry, mass properties, aerodynamics, propulsion and operational environment affect the vehicle flight dynamics, and (3) demonstrate ability to perform simulations of the aircraft longitudinal and lateral-directional dynamics (linear) and to learn methods of automatic control (linear) of the 
aircraft to obtain desired handling qualities. This course currently employs traditional quizzes, homework, projects and tests to assess students' educational outcomes. In this CDIO-inspired course redesign we intend to revise our approach to measure educational outcomes by employing critical reflection and retrospective surveys to understand the impact on student learning and the value of CDIO approach to students. We present course educational outcomes, current assessment approaches and proposed assessment approach in Table 3.

Table 3: Proposed Revised Assessment Approach

\begin{tabular}{|c|c|c|}
\hline Educational Outcomes & Current Assessment & $\begin{array}{l}\text { Proposed Assessment } \\
\text { Additions }\end{array}$ \\
\hline $\begin{array}{l}\text { 1. Ability to derive the fundamental } \\
\text { equations that describe the aircraft } \\
\text { dynamics as well as to determine the } \\
\text { stability and flight control } \\
\text { characteristics of an aircraft. }\end{array}$ & $\begin{array}{l}\text { Regularly scheduled in-class } \\
\text { quizzes, and tests }\end{array}$ & \\
\hline $\begin{array}{l}\text { 2. To understand how the design } \\
\text { parameters related to aircraft } \\
\text { geometry, mass properties, } \\
\text { aerodynamics, propulsion and } \\
\text { operational environment affect the } \\
\text { vehicle flight dynamics. }\end{array}$ & (same as above) & \\
\hline $\begin{array}{l}\text { 3. To be able to perform simulations of } \\
\text { the aircraft longitudinal and lateral- } \\
\text { directional dynamics (linear) and to } \\
\text { learn methods of automatic control } \\
\text { (linear) of the aircraft to obtain } \\
\text { desired dynamic characteristics. }\end{array}$ & $\begin{array}{l}\text { Simulations in software; group } \\
\text { projects in Matlab; }\end{array}$ & $\begin{array}{l}\text { Group projects in Matlab } \\
\text { followed by flight test } \\
\text { evaluations of the performance } \\
\text { of the student designed flight } \\
\text { control algorithms }\end{array}$ \\
\hline
\end{tabular}

In this course redesign, we are interested in understanding whether this approach (1) helps students think critically about aircraft stability and control and whether (2) students positively receive the field experience. We will use Rolfe et. al.'s "What? So what? Now what?" model in which thinking and practice are integrated through experiential learning (Rolfe et al, 2011). Reflective approaches in undergraduate education have been shown to strengthen emotional intelligence, encourage confidence, bolster decision making, promote meaningful learning, and support complex topic acquisition through reflexive review of skills throughout development (Ash, 2009, Bolton, 2010, Thompson \& Pascal, 2012, and Black \& Plowright, 2010). Students in this course will be tasked with a three-part guided exercise to prompt them through a critical reflection of their UAS field experience and how experiences in the field connect to classroom concepts.

Part One: "What?" emphasizes observations of the experience. Through measurable evidence students will build a descriptive account of the experience by answering questions such as "what am I trying to achieve?" and "what happened?" during their UAS field experience.

Part Two: "So What?" in which students will infer meaning through analysis of the experience by answering questions such as "so what is this importance of this?" and "so what more do I need to know about this?" directly after their UAS field experience.

Part Three: "Now What?" students will synthesize previous answers to consider alternative actions and build deeper level of understanding with questions such as "now what might be the consequences of this action?" and "now what do I need to do to repeat/stop/change 
a particular action?" by drawing upon classroom content and applying it to alternative UAS outcomes.

Note that this process is non-linear. Students could (will) repeat Parts One through Three during their next UAS field experience. Student-produced reflections will be analyzed for content mastery and concept connections made between in-class material and hands-on UAS field experiences. We will map course concepts and experiential learning opportunities to a rubric for assessing the accuracy of students' inferred meaning and considered alternatives in relation to the observations they made during their UAS field experience. The goal of using reflections, as opposed to alternative assessments, it to gain insight into the ways students experience the concepts as well as construct meaning from the UAS experiences.

Further, we will employ a retrospective survey and post survey to measure students' reception of the field experience of the CDIO approach. Programmatic changes are often measured by pre/post-surveys in which pre-survey responses are compared to post-survey responses in an effort to understand which aspects of the program did or did not impact participants. This technique, however, does not take into account changes in frame of reference, or response shift bias, that may occur as a result of participating in the program or, in the context described herein, participating in the learning experience (Drennan \& Hyde, 2008). In an effort to minimize the confounding factor of response shift bias, student perceptions of the course will be collected at the same time for both surveys; retrospective survey will capture students' pre-course value perceptions at the same time post-course value perceptions are captured. We present sample survey questions in Table 4.

Table 4: Sample Retrospective and Post-Survey Questions

\begin{tabular}{|c|c|c|c|c|c|c|c|c|}
\hline \multirow[b]{2}{*}{$\begin{array}{l}\text { 1. Ability to determine the stability and flight } \\
\text { control characteristics of an aircraft }\end{array}$} & \multicolumn{4}{|c|}{$\begin{array}{l}\text { Retrospective Survey } \\
\text { Before the hands-on } \\
\text { component, indicate your } \\
\text { confidence in ability to } \\
\text { perform the task: }\end{array}$} & \multicolumn{4}{|c|}{$\begin{array}{l}\text { Post Survey } \\
\text { After the hands-on } \\
\text { component, indicate your } \\
\text { confidence in ability to } \\
\text { perform the task: }\end{array}$} \\
\hline & None & Low & Mod & High & None & Low & Mod & High \\
\hline $\begin{array}{l}\text { 2. To understand how the design parameters } \\
\text { related to aircraft geometry, mass } \\
\text { properties, aerodynamics, propulsion and } \\
\text { operational environment affect the vehicle } \\
\text { flight dynamics }\end{array}$ & None & Low & Mod & High & None & Low & Mod & High \\
\hline $\begin{array}{l}\text { 3. To be able to perform simulations of the } \\
\text { aircraft longitudinal and lateral-directional } \\
\text { dynamics (linear) }\end{array}$ & None & Low & Mod & High & None & Low & Mod & High \\
\hline $\begin{array}{l}\text { 4. To apply methods of automatic control } \\
\text { (linear) to an aircraft (UAS) and obtain } \\
\text { desired dynamic performance. }\end{array}$ & None & Low & Mod & High & None & Low & Mod & High \\
\hline $\begin{array}{l}\text { 5. To apply concepts and methods covered in } \\
\text { the course in a real-world setting. }\end{array}$ & None & Low & Mod & High & None & Low & Mod & High \\
\hline $\begin{array}{l}\text { 6. Explain differences between anticipated and } \\
\text { measured UAS performance }\end{array}$ & None & Low & Mod & High & None & Low & Mod & High \\
\hline
\end{tabular}

None $=$ no confidence, cannot perform task

Low $=$ low confidence, uncertain in ability to perform task

Moderate $=$ moderate confidence, somewhat confident in ability to perform task

High $=$ high confidence, certain in ability to perform task 


\section{Future Direction}

We anticipate that the results from the impact on learning and student perspective of value will be used to evaluate the CDIO based redesign approach. The feedback from the students will be used to identify successes and equally importantly, the key points of pain; these are opportunities for improvement of the redesign approach. From this body of work, we will produce lessons learned for redesigning a course curriculum using CDIO approach, particularly for upper division classes in aerospace engineering and implementing hands-on design and testing modules and share key pivot points that influenced the educational outcomes for students. In the longer term, we anticipate partnering with other academic institutions to offer the services of our UAS for use within their classroom. We also intend to open source the data collected from the flight tests of our UAS, and the aerodynamic parameters extracted from that; we hope that this would allow other aerospace engineering programs anywhere to design, develop and simulate their own flight control algorithms, and partner with us to experimentally validate the same. As a derivative benefit, we believe that this would open up avenues for further growth of our students by improving their communication, presentation and team work skills.

\section{References}

Ash, S. L., \& Clayton, P. H. (2009). Generating, deepening, and documenting learning: The power of critical reflection in applied learning.

Black, P. E., \& Plowright, D. (2010). A multi-dimensional model of reflective learning for professional development. Reflective Practice, 11(2), 245-258. doi:10.1080/14623941003665810

Bolton, G. (2010). Reflective practice: Writing and professional development. Sage publications.

Drennan, J., \& Hyde, A. (2008). Controlling response shift bias: the use of the retrospective pre- test design in the evaluation of a master's programme. Assessment \& Evaluation in Higher Education, 33(6), 699-709.

Rolfe, G., Freshwater, D., \& Jasper, M. (2011). Critical reflection in practice (2nd ed.). Houndmills, Basingstoke, Hampshire ; New York, N.Y.: Palgrave.

Thompson, N., \& Pascal, J. (2012). Developing critically reflective practice. Reflective practice, 13(2), 311-325.

History of the Worldwide CDIO Initiative, http://www.cdio.org/cdio-history, accessed $03 / 21 / 2019$

Säisä, M., Määttä, S., Roslöf, J., "Integration of CDIO Skills into Project-Based Learning in Higher Education", Proceedings of the $13^{\text {th }}$ International CDIO Conference in Calgary, Canada. 2017

Takemata, K., Kodaka, A., Minamide, A. and Nakamura, S., "Engineering project-based learning under the CDIO concept", Proc. IEEE Inter. Conf. on Teaching, Assessment and Learning for Engng., 258-261 (2013). 
Svensson, T. and Gunnarsson, S., "A design-build-test course in electronics based on the CDIO framework for engineering education", Inter. J. of Electrical Engng. Educ., 49, 4, 349-364 (2012).

Hsu, J.C. and Raghunathan, S., "Systems engineering for CDIO conceive, design, implement and operate", Collection of Technical Papers - 45th AIAA Aerospace Sciences Meeting, 7119-7129 (2007). https://doi.org/10.2514/6.2007-591 


\section{AENG 4400 - Stability and Control, Fall 2018 \\ Department of Aerospace and Mechanical Engineering}

Instructor: Srikanth Gururajan

Email: srikanth.gururajan@slu.edu, Room 2049 MDH

Phone: (314) 977-8355

\section{Class and Office Hours}

Class: Tuesday and Thursday - 9:30 a.m. to 10:45 a.m.

Office Hours: Tuesday - 12:00 noon to 1:00 p.m.

Final: Tuesday, December $18^{\text {th }}$, 2018. 8:00 a.m. - 9:50 a.m.

Text Book: $\quad$ Aircraft Dynamics: From Modeling to Simulation $1^{\text {st }}$ Edition, by Napolitano

Note: The instructor will also provide a number of handouts and other supporting materials for the class.

(a) Description: This course aims to provide the students the fundamental concepts of modeling of aircraft dynamics. It also describes the static and dynamic stability and flight control characteristics of an aircraft in its longitudinal and lateral - directional motions. The analysis of the aircraft dynamics will be performed using Matlab ${ }^{\circledR}$. Additional concepts related to aircraft flight dynamics, simulation and control will also be covered. The material presented in this course will help to prepare the student to conduct capstone design of an aircraft from specifications, in their senior year of the program.

(b) Pre-Requisites: AENG 3000 Performance, ESCI 3410 ACLS (Concurrent)

(c) Required/Elective: Required Course

\section{Course Outcomes:}

1. Ability to derive the fundamental equations that describe the aircraft dynamics as well as to determine the stability and flight control characteristics of an aircraft.

2. To understand how the design parameters related to aircraft geometry, mass properties, aerodynamics, propulsion and operational environment affect the vehicle flight dynamics.

3. To be able to perform simulations of the aircraft longitudinal and lateral-directional dynamics (linear) and to learn methods of automatic control (linear) of the aircraft to obtain desired handling qualities.

Student Outcomes addressed by the course:

ABET Criterion 3 - (a), (c), (e), (k)

Grading Policy:

$\begin{array}{ll}\text { Quizzes } & 10 \% \\ \text { Homework } & 10 \% \\ \text { Midterm Exams (2) } & 30 \% \\ \text { Project(s) } & 25 \% \\ \text { Final Exam (Comprehensive) } & 25 \%\end{array}$

The final grade in this course will be assigned using the scale:

$\begin{array}{llllll}>92 & - & \text { A } & >76 \leq 79 & - & \text { C+ } \\ >88 \leq 92 & - & \text { A- } & >73 \leq 76 & - & \text { C } \\ >85 \leq 88 & - & \text { B+ } & >70 \leq 73 & - & \text { C- } \\ >82 \leq 85 & - & \text { B } & >60 \leq 70 & - & \text { D } \\ >79 \leq 82 & - & \text { B- } & \leq 60 & - & \text { F }\end{array}$


Negotiation for Grades: The only way to achieve the minimum grade that you require is to attend every class, study suitably for exams, and successfully complete all assignments and projects.

Excused absence policy: Class attendance is mandatory; attendance will be noted every class. The only justifiable absences will be those according to official SLU policies. Legitimate conflicts and excuses require written documentation, and are limited to a student's illness that requires immediate doctor's care, a University sponsored event (not club sports) and regularly scheduled religious obligations. Excuses that will NOT be considered include personal travel arrangements, non-University sponsored events, a conflicting appointment, a previous illness that interfered with your study time or an illness that does not prevent you from coming to the exam. Unexcused exam absences will be counted as zero in the calculation of your final grade.

\section{Topics:}

i. Derivation of the equations of motion of a rigid aircraft.

ii. Review of background material on Aerodynamics.

iii. Modeling of aerodynamic and thrust forces and moments.

iv. Static stability and controls in longitudinal and lateral - directional motion.

v. Longitudinal and Lateral-directional dynamic stability.

vi. Stability sensitivity analysis.

vii. Aircraft response to control inputs; manual and automatic control of flight; stability augmentation system (SAS) design; classical and state space methods design and analysis.

viii. Other pertinent topics may be covered at the discretion of the instructor and availability of time. 


\section{AENG 4400 - Stability and Control, Fall 2019 \\ Department of Aerospace and Mechanical Engineering}

Instructor: Srikanth Gururajan

Email: srikanth.gururajan@slu.edu, Room 2049 MDH

Phone: (314) 977-8355

Class and Office Hours

Class: TBD

Office Hours: TBD

Final: $T B D$

Text Book:

TBD

Note: The instructor will also provide a number of handouts and other supporting materials for the class.

(a) Description: This course aims to provide the students the fundamental concepts of modeling of aircraft dynamics. It also describes the static and dynamic stability and flight control characteristics of an aircraft in its longitudinal and lateral - directional motions. The analysis of the aircraft dynamics will be performed using Matlab ${ }^{\circledR}$. Additional concepts related to aircraft flight dynamics, simulation and control will also be covered. The material presented in this course will help to prepare the student to conduct capstone design of an aircraft from specifications, in their senior year of the program.

(b) Pre-Requisites: AENG 3000 Performance, ESCI 3410 ACLS (Concurrent)

(c) Required/Elective: Required Course

Course Outcomes:

1. Ability to derive the fundamental equations that describe the aircraft dynamics as well as to determine the stability and flight control characteristics of an aircraft.

2. To understand how the design parameters related to aircraft geometry, mass properties, aerodynamics, propulsion and operational environment affect the vehicle flight dynamics.

3. To be able to perform simulations of the aircraft longitudinal and lateral-directional dynamics (linear) and to learn methods of automatic control (linear) of the aircraft to obtain desired handling qualities.

Student Outcomes addressed by the course:

ABET Criterion 3 - (a), (c), (e), (k)

Grading Policy:

$\begin{array}{ll}\text { Quizzes } & 10 \% \\ \text { Homework } & 10 \% \\ \text { Midterm Exams (2) } & 30 \% \\ \text { Project(s) } & 25 \% \\ \text { Final Exam (Comprehensive) } & 25 \%\end{array}$

The final grade in this course will be assigned using the scale:

$\begin{array}{llllll}>92 & - & \text { A } & >76 \leq 79 & - & \text { C+ } \\ >88 \leq 92 & - & \text { A- } & >73 \leq 76 & - & \text { C } \\ >85 \leq 88 & - & \text { B+ } & >70 \leq 73 & - & \text { C- } \\ >82 \leq 85 & - & \text { B } & >60 \leq 70 & - & \text { D } \\ >79 \leq 82 & - & \text { B- } & \leq 60 & - & \text { F }\end{array}$




\section{APPENDIX B - REVISED CDIO BASED SYLLABUS}

Negotiation for Grades: The only way to achieve the minimum grade that you require is to attend every class, study suitably for exams, and successfully complete all assignments and projects.

Excused absence policy: Class attendance is mandatory; attendance will be noted every class. The only justifiable absences will be those according to official SLU policies. Legitimate conflicts and excuses require written documentation, and are limited to a student's illness that requires immediate doctor's care, a University sponsored event (not club sports) and regularly scheduled religious obligations. Excuses that will NOT be considered include personal travel arrangements, non-University sponsored events, a conflicting appointment, a previous illness that interfered with your study time or an illness that does not prevent you from coming to the exam. Unexcused exam absences will be counted as zero in the calculation of your final grade.

\section{Topics:}

i. Derivation of the equations of motion of a rigid aircraft.

ii. Review of background material on Aerodynamics.

iii. Modeling of aerodynamic and thrust forces and moments.

iv. Static stability and controls in longitudinal and lateral - directional motion.

v. Longitudinal and Lateral-directional dynamic stability.

vi. Stability sensitivity analysis.

vii. Aircraft response to control inputs; manual and automatic control of flight; stability augmentation system (SAS) design; classical and state space methods design and analysis.

viii. Hands-on experimental flight testing and validation of the concepts of aircraft dynamics

ix. Other pertinent topics may be covered at the discretion of the instructor and availability of time. 